\title{
Reflexive and Reciprocal Encoding in the Australian Mixed Language, Light Warlpiri
}

\author{
Carmel O'Shannessy ${ }^{1, *}$ and Connor Brown ${ }^{2} \mathbb{D}$ \\ 1 School of Literature, Languages and Linguistics, College of Arts and Social Sciences, \\ Australian National University, Canberra, ACT 2600, Australia \\ 2 School of Social Sciences, The University of Western Australia, Perth, WA 6009, Australia; \\ connor.brown@research.uwa.edu.au \\ * Correspondence: Carmel.O'Shannessy@anu.edu.au
}

check for updates

Citation: O'Shannessy, Carmel, and Connor Brown. 2021. Reflexive and Reciprocal Encoding in the Australian Mixed Language, Light Warlpiri. Languages 6: 105. https://doi.org/ 10.3390/languages6020105

Academic Editors: Juana M. Liceras and Raquel Fernández Fuertes

Received: 28 January 2021

Accepted: 19 May 2021

Published: 10 June 2021

Publisher's Note: MDPI stays neutral with regard to jurisdictional claims in published maps and institutional affiliations.

Copyright: (C) 2021 by the authors Licensee MDPI, Basel, Switzerland. This article is an open access article distributed under the terms and conditions of the Creative Commons Attribution (CC BY) license (https:// creativecommons.org/licenses/by/ $4.0 /)$.

\begin{abstract}
Mixed languages combine significant amounts of grammatical and lexical material from more than one source language in systematic ways. The Australian mixed language, Light Warlpiri, combines nominal morphology from Warlpiri with verbal morphology from Kriol (an English-lexified Creole) and English, with innovations. The source languages of Light Warlpiri differ in how they encode reflexives and reciprocals-Warlpiri uses an auxiliary clitic for both reflexive and reciprocal expression, while English and Kriol both use pronominal forms, and largely have separate forms for reflexives and reciprocals. English distinguishes person and number in reflexives, but not in reciprocals; the other source languages do not distinguish person or number. This study draws on naturalistic and elicited production data to examine how reflexive and reciprocal events are encoded in Light Warlpiri. The study finds that Light Warlpiri combines near-maximal distinctions from the source languages, but in a way that is not a mirror of any. It retains the person and number distinctions of English reflexives and extends them to reciprocals, using the same forms for reflexives and reciprocals (like Warlpiri). Reflexives and reciprocals occur within a verbal structure (perhaps under influence from Warlpiri). The results show that a mixed language can have discrete contributions from three languages, that the source languages can influence different subsystems to different extents, and that near-maximal distinctions from the source languages can be maintained.
\end{abstract}

Keywords: Warlpiri; Light Warlpiri; reflexive; reciprocal; Australia; endangered language; PamaNyungan; Kriol; mixed language; language contact

\section{Introduction}

Mixed languages combine significant amounts of structural and lexical material from two or more languages in a systematic way, so much so that they cannot be said to have only a single parent language (Matras and Bakker 2003; Thomason and Kaufman 1988, p. 12). Although there are general typologies of source language combination (Matras 2003; O'Shannessy 2021a; Thomason 2003), each mixed language may show differences in how source language materials are configured in different subsystems. In an area where the source languages show differing typologies, how the differences will be resolved in each part of the grammar is an open question.

The Australian mixed language, Light Warlpiri, combines elements of three source languages in a conventionalised structure. The three languages can be categorised into two types in terms of lexifier language and type of structure. Warlpiri, a Pama-Nyungan language with an agglutinative structure, is of one type, and provides the nominal structure of Light Warlpiri. The other type includes both English and Kriol, separate English-lexified languages that are isolating in structure, and provide the verbal structure, with innovations. Kriol is an English-lexified Creole spoken across the north of Australia. 
The focus of this paper is an area where the source languages of Light Warlpiri clearly differ-in the encoding of reflexive and reciprocal constructions, with a threeway distinction between them. English and Kriol provide the verbal structural frame of Light Warlpiri, but they do not use verbal morphosyntax to encode reflexives and reciprocals. English has separate pronominal forms for reflexives versus reciprocals, and only reflexives distinguish person and number (e.g., myself, yourself, themselves). Most varieties of Kriol also have separate pronominal forms for reflexives and reciprocals (forms related to mijelp < English myself), but neither of those distinguishes person and number. Warlpiri provides the nominal structure of Light Warlpiri, but reflexives and reciprocals are not encoded in nominal structure in Warlpiri. Warlpiri encodes reflexives and reciprocals with a pronominal clitic in the auxiliary, =nyanu, and also does not distinguish person and number.

There is in effect a gap in source language material for encoding reflexives and reciprocals in Light Warlpiri. This raises the question of how reflexives and reciprocals are encoded, and has implications for what might be expected in the structures of mixed languages. Are the forms and structures of one language retained to the exclusion of those of the others? Or are all of the source language features combined in some way, and if so, how? Will there be a simplification of the morphology of the source languages, or will all, or most, distinctions be retained? A further question relates to semantic scope-which types of events are expressed using morphological reciprocal constructions, and how do they compare to the source languages?

This paper describes the encoding of reflexive and reciprocal events in Light Warlpiri, examining both structure and semantics, and showing how the differences in source languages play out in the mixed language. It reports on naturalistic data for both categories, and on a dedicated elicited production study about the semantic scope of reciprocals (cf. Evans et al. 2011).

Background to the structure of Light Warlpiri is given in Section 2, and background to the crosslinguistic encoding of reflexives and reciprocals is given in Section 3, including details of the source languages of Light Warlpiri: Warlpiri, English and Kriol. Section 4 describes the methodology of the study. In Section 5, the reflexive and reciprocal system of Light Warlpiri is described, including the semantic scope of reciprocal constructions. Section 6 discusses Light Warlpiri reflexives and reciprocals in comparison to its source languages and the implications for typologies of mixed languages, and Section 7 concludes.

\section{Background to Light Warlpiri}

Light Warlpiri is an Australian Mixed Language that emerged in the 1970s-80s in the remote Warlpiri community of Lajamanu, in the Northern Territory. It combines Warlpiri (Pama-Nyungan) nominal morphology with Kriol and English verbal morphology and structural innovations in the verbal auxiliary system (O'Shannessy 2005, 2013). In the examples elements from Warlpiri are in italics, and elements from English and Kriol are in plain font.

\begin{tabular}{|c|c|}
\hline $\mathrm{u}=\mathrm{m}$ & hit-im \\
\hline
\end{tabular}

"You hit him."

(2015Elicit_LW_LA21_LAC58)

Example (1) shows an English-derived transitive verb hit 'hit' with a Kriol transitive marker -im 'TR'. The auxiliary consists of an English and Kriol-derived weak pronoun yu '2SG' with an innovative morpheme $=m$ 'NFUT' attached (O'Shannessy 2013). The subject

1 Abbreviations: 1 '1st person', 2 '2nd person', 3 '3rd person', ALL 'allative', CAUS 'causative', COM 'comitative', COORD 'coordinator', DAT 'dative', DEM 'demonstrative', DET 'determiner', DIM 'diminutive', DIS 'discourse marker', D 'dual', EXCL 'exclusive', EMPH 'emphatic', ERG 'ergative', FUT 'future', IMP 'imperative', INCHO 'inchoative', INCL 'inclusive', INF 'infinitive', ITER 'iterative', LOC 'locative', NFUT 'nonfuture', NPST 'nonpast', O 'object', PAUC 'paucal', PL 'plural', PRES 'present', PRIV 'privative', PROG 'progressive', PST 'past', RECIP 'reciprocal', REFL 'reflexive', REL 'relativiser', S 'subject', SG 'singular', TOP 'topic', TR 'transitive'. 
of the transitive verb, nyuntu '2SG' is a free, or strong, pronoun from Warlpiri and in this clause takes a Warlpiri ergative case-marker -ngu 'ERG'. In Light Warlpiri free, or strong, pronouns are from Warlpiri and bound, or weak, pronouns are from English and/or Kriol, e.g., yu ' $2 \mathrm{SG}^{\prime}$ ' in (1). The auxiliary is categorised as part of the verbal complex, as it inflects for tense-mood-aspect (TMA) and functions in concert with inflections on the lexical verb to realise specific TMA readings (O'Shannessy 2005). In addition, in LW the auxiliary and verb are always adjacent, no other material can occur between them.

Lajamanu community has a population of approximately 600 , and was formed in 1948-49 when Warlpiri people were relocated there by the government (Berndt and Berndt 1987; Rowse 2002) - the new way of speaking is a legacy of this relocation. In the 1950s-70s Warlpiri adults worked on cattle stations, some of them hundreds of kilometres from the community and Warlpiri lands (Tasman and O'Shannessy 2020), and interacted with speakers of many traditional languages as well as English. They probably spoke in an emerging Creole, now called Kriol, that was diffusing across the north of Australia at that time.

In Lajamanu, when speaking to other Warlpiri, people code-switched between Warlpiri, Kriol and/or English, and this way of speaking became common. When adults spoke to very young children their code-switched speech followed a particular pattern, where a Kriol pronoun and verb were inserted into a Warlpiri string, as part of a Baby Talk register (O'Shannessy 2012), as in (2).

\begin{tabular}{|c|c|c|c|c|c|c|c|}
\hline $\begin{array}{l}\text { yakarra } \\
\text { DIS }\end{array}$ & $\begin{array}{l}\text { nyanya } \\
\text { food }\end{array}$ & $\begin{array}{l}\text { wi } \\
\text { 1PL }\end{array}$ & $\begin{array}{l}\text { hab-im } \\
\text { have-TR }\end{array}$ & $\begin{array}{l}\text { nyanya } \\
\text { food }\end{array}$ & $\begin{array}{l}\text { wana } \\
\text { DIS }\end{array}$ & $\begin{array}{l}\text { ngalipa } \\
\text { 1PL.INCL }\end{array}$ & $\begin{array}{l}\text { nyanya } \\
\text { food }\end{array}$ \\
\hline
\end{tabular}

(O’Shannessy 2012, p. 325)

In example (2) a woman in her forties, older than the Light Warlpiri-speaking cohort was at the time of recording, is speaking to a two-year-old child. She produces a Warlpiri string with the insertion of a Kriol pronoun and verb. This pattern of code-switching was commonly used with very young children. The word nyanya 'food' is only used in a Baby Talk register (Laughren 1984), it is not one of the words for food that adults use when speaking with other adults.

Young children internalised the code-switched speech as a single system, differentiating it from Warlpiri (O'Shannessy 2020). They conventionalised it into a systematic way of speaking, and in doing so added innovation in the verbal auxiliary system, the $=m$ 'NONFUTURE' suffix seen in (1), explained in detail in O'Shannessy $(2012,2013)$.

That group of children is now aged up to 40 years of age, and Light Warlpiri is the primary way of speaking of that age group and all speakers younger than them. This makes clear that the nearly age 40 group was the innovating cohort and that the new way of speaking was transmitted from them to the next generations. Now, in the 2020s, a third generation of Light Warlpiri speakers is being born; this generation is currently younger than five years old. Light Warlpiri is only spoken in Lajamanu community, and remains the primary language of its speakers, who also learn and speak traditional Warlpiri. In addition, they learn English as they grow up and show some understanding of the languages and varieties of the surrounding area ( $\mathrm{O}^{\prime}$ Shannessy 2018).

The aspect of Light Warlpiri most relevant to the encoding of reflexive and reciprocal meanings is the expression of core arguments and verbs. Light Warlpiri has in common with Warlpiri that core arguments need not be overt. When they are, Light Warlpiri retains the Warlpiri case-marking system almost entirely, as in (3).
3. karnta-pawu-ng
woman-DIM-ERG
$\mathrm{i}=\mathrm{m}$
swing-im-pat swing-TR-ITER
kurdu-pawu
3SG=NFUT child-DIM
"The woman repeatedly swings the child/pushes the child on a swing." 
In (3) the speaker is telling part of a story from picture stimulus (O'Shannessy 2004) in which a child is on a swing, being pushed by a woman. The words for both the subject of the transitive verb, karnta-pawu-ng 'woman-DIM-ERG' and the object, kurdu-pawu 'child-DIM' are from Warlpiri, and the subject is marked with an ergative marker, $-n g$ 'ERG', a reduced form of one ergative allomorph from Warlpiri. Ergative marking occurs on approximately $80 \%$ of overt subjects of transitive verbs, and on $96 \%$ of them when the word order is VS (O'Shannessy 2016). The verb is drawn from English and Kriol, with a Kriol transitive marker, -im 'TR', and iterative marker, -pat 'ITER'. The transitive + iterative structure is directly from Kriol, which also shows a VERB-TR-ITER structure (Schultze-Berndt et al. 2013). In (3) the transitive marker on a typically intransitive verb swing 'swing' makes the verb transitive, with the meaning that the woman is causing the child to swing.

While most lexical verbs in Light Warlpiri are derived from English and Kriol, and have Kriol structure, some have a Warlpiri-derived verb stem, and if transitive, have the Kriol transitive marker attached (Meakins and O'Shannessy 2012; O'Shannessy 2021b).

4.

$\begin{array}{lll}\text { nyiya-ng } & \mathrm{i}=\mathrm{m} & \text { pantirn-im-pat? } \\ \text { What-ERG } & \text { 3SG=NFUT } & \text { pierce-TR-ITER }\end{array}$

"What pierced it?"

(2015ERGstoryLA93)

In (4) the verb pantirn-im-pat 'pierce-TR-ITER' has a Warlpiri-derived verb stem with Kriol-derived transitive and iterative markers attached. The wh-question word takes an ergative case marker because the verb is transitive. This example is provided because it is useful to see that the Kriol iterative marker, which will become relevant in Section 5, can occur following a transitive marker on a Warlpiri-derived verb stem.

Nonsubject pronoun forms (im '3SG', dem '3PL') can occur in Light Warlpiri, as in (5) and (6), but they are not common-the data show fewer than 40 occurrences from thousands of transitive clauses. A full NP or free pronoun can follow and coreference a nonsubject pronoun, as in examples (5) and (6). The question as to why the nonsubject pronouns in (5) and (6) are represented within the verbal word is answered in the analysis of reflexive-reciprocal encoding in Section 6.

5.

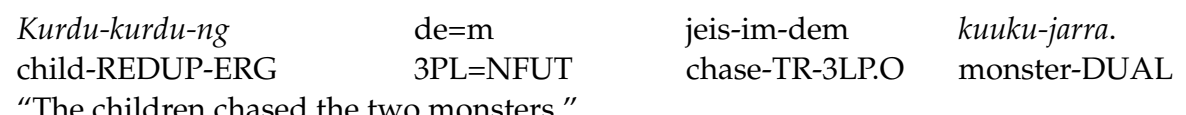

(Recip_LAC43)

6.

$\begin{array}{llll}\begin{array}{l}\text { Kurdu-kurdu-ng } \\ \text { child-REDUP-ERG }\end{array} & \text { de=m } & \text { jeis-im-dem } & \text { nyanungu-rra } \\ \text { 3PL=NFUT } & \text { chase-TR-3LP.O } & \text { 3SG-PL }\end{array}$

"The children chased them."

(Recip_LAC43)

Light Warlpiri incorporates distinctions amalgamated from its source languages in several ways. For instance, a near-maximal combination is seen in the phonological system, where the plosive series of consonants shows the near-maximal incorporation of voicing and place of articulation distinctions from the source languages (Bundgaard-Nielsen and O'Shannessy 2021). Light Warlpiri maintains an inclusive-exclusive pronominal distinction (from Warlpiri) to some extent, and partially a singular, dual and plural number distinction, present in both Warlpiri and Kriol.

In this section, the features of Light Warlpiri most needed to understand the encoding of reflexive and reciprocal events are described. The next section contextualises the encoding of reflexive and reciprocal events in Light Warlpiri by discussing the encoding crosslinguistically. 


\section{Encoding of Reflexive and Reciprocal Expressions Cross-Linguistically}

\subsection{The Structural Encoding of Reflexive and Reciprocal Constructions Cross-Linguistically}

Reflexive and reciprocal domains are closely linked as they both involve coreference of subject and object arguments in the expression of certain event types. Prototypically, reflexivity expresses an event where an agent of an action is also the recipient of that action; reciprocity can be conceptualised as an event in which two or more agents perform an action upon each other (Heine and Miyashita 2008, p. 169). Reflexives can show coreference between all grammatical persons and numbers (e.g., English myself, yourself, themselves) while reciprocals only refer to events with more than one participant entity (e.g., English each other).

Reflexive and reciprocal events can each be expressed using a wide range of grammatical construction types. Comprehensive crosslinguistic reviews of reciprocals and reflexives are given in, e.g., Frajzyngier and Curl (1999); Janic et al. (2021); Konig and Gast (2008); Faltz (1977); Nedjalkov (2007) and Evans et al. (2011). In some languages, reflexives and reciprocals are encoded with separate forms for each, in others with the same form for both. The expression of both reflexive and reciprocal functions with a single form occurs in about one-third of languages (Evans et al. 2011, p. 20; Heine and Miyashita 2008, p. 171), and occurs very consistently in Australian languages (Dixon 1980, p. 433).

The most commonly documented ways of encoding reflexive expressions are reflexive nominals (including pronouns), reflexive voice markers (verbal affixes or clitics) and reflexive argument markers (bound pronominal clitics) (Haspelmath Forthcoming, p. 15). Less frequent constructions include, e.g., bipartite reflexive pronouns, adverbial forms, and logophoric pronouns, where the coreference is between the subject of a matrix clause and a participant in an embedded clause (Haspelmath Forthcoming, p. 20). Each of the three major types can be further categorised into smaller groupings, for details see Haspelmath (Forthcoming). Reflexive expressions rarely have an exclusively reflexive meaning, and can also express reciprocal, applicative, inchoative, middle, intensifier and evaluative type functions (Déchaine and Wiltschko 2017). In addition to specialized reflexive marking, languages often have a restricted class of inherently reflexive verbs, where reflexive meaning is inherent within the lexical semantics of the verb, so other types of reflexive marking are not present.

Reciprocals may show the largest variety of means of expression of any grammatical category, and may be encoded by nominals and pronominals, adverbs, auxiliaries, verbal or pronominal affixes or clitics, or multi-clause structures (Evans et al. 2011, p. 15). In some languages, reciprocals are encoded by more than one type of structure, e.g., both verbal and pronominal (Evans et al. 2011).

Languages often have one primary, productive means of grammatically expressing reflexivity and reciprocity in addition to a number of semi-productive and secondary strategies, which are typically semantically or morphosyntactically restricted. The expression of both reflexive and reciprocal functions with a single linguistic form is well-attested crosslinguistically, and has been demonstrated to be the result of grammaticalization processes, where reflexive forms acquire reciprocal functions over time (Heine and Miyashita 2008). In some languages, a shared form can show variable morphosyntactic behaviour, e.g., both verbal and (pro)nominal.

In sum, reflexives and reciprocals can be encoded in a variety of grammatical construction types. They may be expressed nominally or verbally or in both structures, and approximately one-third of languages use a shared form for the two functions.

\section{Mixed Languages}

Mixed languages are intriguing because the sources of a language may encode reflexivity and reciprocity in different ways, and if they do, there is no clear a priori prediction about the structures that would result in the mixed language. Yet comparatively little detailed analysis of how these categories are expressed in mixed languages is available. 
Michif, a mixed language of the Métis of Canada, has a nominal system inherited from Canadian French and a verbal system inherited from Plains Cree, with no apparent simplification of either system (Bakker 1997). In keeping with the verbal system of Michif being from Plains Cree, the synthetic verbal reflexive and reciprocal affixes of Plains Cree have been retained in Michif. The reflexive affix takes the form -iso- 'REFL' while the reciprocal takes the form -ito- 'RECIP' (Bakker 1997, p. 98).

Gurindji Kriol, spoken in Australia, also combines nominal morphology from one source language, Gurindji (Pama-Nyungan), and verbal morphology from Kriol (McConvell and Meakins 2005). In Gurindji Kriol, reciprocity and reflexivity is expressed through a single pronominal form mijelp 'REFL', derived from the Kriol reflexive marker of the same form (Meakins 2011, p. 45). The use of a single form is likely under influence from Gurindji (Meakins 2011, p. 45) as well as Kriol varieties in the west, which have a single form to express both categories.

A mixed language with a different structure, Media Lengua, which has a Spanish lexicon with Quechua morphology, is spoken in Ecuador (Muysken 1997). In keeping with Quechua verbal morphology, the Quechua reflexive -ri 'REFL' and reciprocal -naku 'RECIP' forms are present in Media Lengua (Muysken 1981).

The patterning of reflexives and reciprocals in mixed languages in terms of the relative influences of the source languages is given in Table 1.

Table 1. Influence of source languages in reflexive and reciprocal patterning in three mixed languages.

\begin{tabular}{ccc}
\hline \multicolumn{3}{c}{ Reflexive and Reciprocal Patterning Shows Influence of: } \\
\hline Language & Ancestral source language & Newer source language \\
Michif & $\checkmark$ & \\
Media Lengua & $\checkmark$ & $\checkmark$ \\
Gurindji Kriol & $\checkmark$ & \\
\hline
\end{tabular}

\subsection{The Semantic Scope of Reciprocal Expressions Cross-Linguistically}

A crosslinguistic study of the semantic typology of reciprocal expressions used an extensional method that is drawn on in the current study, and described in Section 4 (Majid et al. 2011). This method uses a set of stimuli videos to explore how speakers express a range of potentially reciprocal event types, with manipulations of number of participants, whether actions are performed simultaneously or sequentially, whether they are performed symmetrically (each on the other) or asymmetrically, and the type of configuration of participants, e.g., a pair, chain, a ring. The study of 20 languages found that there was considerable agreement as to which kinds of events elicited reciprocal constructions, yet one language doesn't use any (Kilivila, Oceanic (Senft 2011)), and some languages encoded fewer types of events with a reciprocal construction than most others (Majid et al. 2011). As an overview, canonical reciprocal events in which each participant acts on the others simultaneously are more likely to receive reciprocal encoding, and asymmetrical actions (one participant acts on the other but the action is not returned) are less likely to receive reciprocal encoding. In general, events with chained actions or melee actions (several participants act on each other but not in a pair-wise, symmetrical manner) are less likely to receive reciprocal encoding. Languages differ as to, for instance, whether a chained action event or a situation of being 'next to' or 'leaning against' something, or an involuntary action such as 'bump', could elicit a reciprocal construction. Whether the type of construction was nominal, verbal or of another type did not correlate with the type of event it encoded (Majid et al. 2011, p. 50).

\subsection{Reciprocals and Reflexives in the Source Languages of Light Warlpiri}

This section provides a brief overview of the relevant structural and semantic features of reflexive and reciprocal expressions in the source languages of Light Warlpiri, in the order Warlpiri, English, then Kriol. 


\subsubsection{Warlpiri}

Warlpiri is a Pama-Nyungan language of the Ngumpin-Yapa subgroup (Laughren and McConvell 2004), spoken primarily in small communities in the Tanami Desert region of the Northern Territory, Lajamanu, Nyirrpi, Yuendumu and Willowra, and in regional towns and cities. Warlpiri has agglutinative structure and declarative finite verbal clauses minimally contain an auxiliary and verb, as in (7c), however, the auxiliary and verb do not need to be adjacent, and other material can appear between them. Core arguments, present in $(7 b)$, are typically elided if the referent(s) can be identified anaphorically. In example (7), the referents of the subject clitic =lu '3PL.S' in (7c) are the man, woman and child who are the transitive subject argument in $(7 \mathrm{~b})$, and the referents of the nonsubject clitic =jana '3PL.O' in (7c) are the bullock and horse who are the subject argument of the intransitive clause in $(7 a)$.

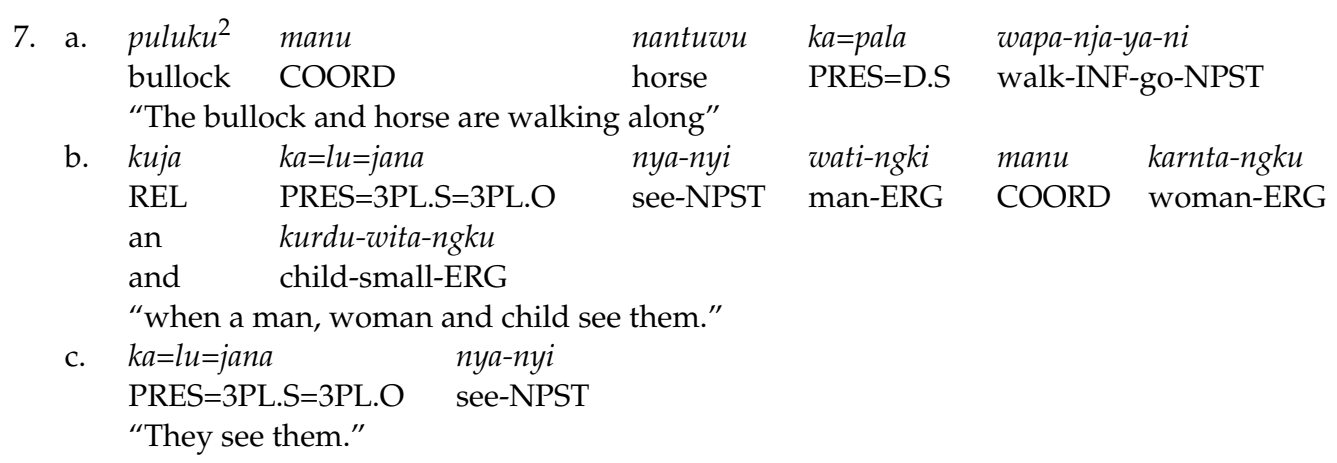

(2010ERGstory_YWA03)

The auxiliary contains a tense-mood-aspect (TMA) element $k a$ 'PRES' that combines with verbal tense affixes to give TMA readings, and hosts pronominal clitics that coreference entities that may or may not be overt in the clause. In past tense clauses, the TMA element of the auxiliary has a null realisation, and the pronominal clitics attach to the first constituent in the clause. The clitics that coreference subject and nonsubject arguments occur in subjectnonsubject order, with exceptions for some combinations of person and number (Hale 1973; Hale et al. 1995).

Warlpiri encodes both reflexive and reciprocal meaning through the use of a single clitic =nyanu appearing in the nonsubject slot in the auxiliary complex (Hale et al. 1995, p. 1437). It coreferences a (transitive or intransitive) subject argument with an absolutive, dative or adjunct dative nonsubject argument (Granites and Laughren 2001; Hale et al. 1995, pp. 1436-439; Laughren Forthcoming, p. 540). Warlpiri does not have a free or bound subject reflexive pronoun like that of English 'self' (Laughren Forthcoming, p. 541). An example of the Warlpiri reflexive-reciprocal is given in (8).

$\begin{array}{lll}\text { 8. Ngarrka-jarra-rlu } & k a=\text { pala }=n y a n u & \text { paka-rni } \\ \text { man-DUAL-ERG } & \text { PRES=D.S=RECIP } & \text { strike-NPST }\end{array}$

"The two men are striking themselves/each other."

(Hale et al. 1995, p. 1437, authors' gloss).

In (8) the reflexive-reciprocal =nyanu 'RECIP/REFL' references an ergative subject, 'the two men', and in (9) it references an absolutive subject, wati-patu 'the men'.
9. Wangka-mi
$k a=l u=n y a n u$
PRES=3PL.S=RECIP
wati-patu.

"The men are talking to each other."

(Hale et al. 1995, p. 1437, authors' gloss).

2 puluku is a long-term borrowing from English 'bullock', integrated into Warlpiri phonology. 
10.

$\begin{array}{ll}\text { yarrpi-rni } & \text { nyanungu-ku } \\ \text { light-NPST } & \text { 3SG-DAT }\end{array}$

(Hale et al. 1995, p. 1441, authors' gloss)

In (10) the reflexive coreferences the ergative-marked subject, Jakamarra, and the ethical dative nyanungu ' $3 S G$ '. The reflexive-reciprocal clitic does not change the valency of the verb, as seen in (8) and (10) where the transitive subjects have ergative case marking, as they would in a non-coreferential clause. For comprehensive analyses of types of nonsubject arguments and coreferential constraints in Warlpiri, see Simpson (1991), Hale et al. (1995), Legate (2002) and Laughren (Forthcoming). The Warlpiri reflexive-reciprocal clitic does not distinguish person or number, but there are some constraints on its occurrence with first and second persons and imperative mood clauses. When a clause has a first-person singular subject, the reflexive expression is encoded by a first-person nonsubject pronominal clitic $=j u$ '1SG.O' in the auxiliary cluster (Simpson 1991, p. 164) as in (11).

$\begin{array}{llll}\text { 11. Ngajulu } & k a=r n a=j u & \text { mapa-rni } & \text { yurlpa-ngku. } \\ \text { 1SG } & \text { PRES=1SG.S=1S.O } & \text { rub-NPST } & \text { ochre-ERG } \\ \text { "I paint myself with red ochre." } & & \end{array}$

(Simpson 1991, p. 164)

Warlpiri has free, or strong, pronouns and bound, or weak, pronouns, as shown in (11), where ngaju ' $1 S G$ ' is a free pronoun and -rna '1SG.S' is a bound pronoun, coreferencing $n g a j u$. Bound pronouns reference both subject and nonsubject arguments, and the reflexivereciprocal morpheme forms part of the nonsubject bound pronoun array.

When a clause is in the imperative mood, the second person nonsubject pronominal clitic $=n g k u$ '2SG.O' encodes reflexive meaning with singular subjects, as in (12). If the subject of an imperative clause is non-singular, as in (13), =nyanu 'RECIP/REFL' occurs (Simpson 1991, p. 164).

12.

\author{
Yampi-ya=ngku \\ leave-IMP=2S.O \\ "Don't paint yourself!"
}
13. Yampi-ya=lu=nyanu
Leave-IMP=3PL.S=REFL
“Don't paint yourselves!"

mapa-rninja-wangu-rlu. rub-INF-PRIV-ERG

(Simpson 1991, p. 164)

mapa-rninja-wangu-rlu. rub-INF-PRIV-ERG

(Simpson 1991, p. 164)

Semantic analysis of one Warlpiri speaker's use of reciprocal =nyanu 'RECIP/REFL' along the lines of Majid et al. (2011) is undertaken for this study, and is given in Section 6, in comparison with that of Light Warlpiri.

\subsubsection{English}

For English, we are able to draw on descriptions of both structural and semantic encoding. English employs distinct pronominal reflexive and reciprocal markers. The reflexive marker, a combination of an object or possessive pronominal and -self, distinguishes both grammatical person and number.

14. He washed himself.

15. They washed themselves.

In addition to the pronominal strategy, a number of verbs have inherently reflexive semantics (Levin 1993, pp. 35-36).

Reciprocity in English is formally differentiated from reflexive marking and is primarily expressed with the quantificational pronominal form each other. 
16. Five people [are] chasing each other.

(Hurst and Nordlinger 2011, p. 76)

This form does not appear to impact the valency of the verb in reciprocal event types and it can be used in a wide range of nonsubject syntactic positions including direct and indirect object, prepositional object and possessive constructions (Hurst and Nordlinger 2011, p. 76). Some speakers may also allow the referent of each other to be semantically plural but grammatically singular, such as with collective nouns (Hurst and Nordlinger 2011, p. 77). In addition to each other, English has a number of other strategies to express reciprocity. These include one another, each ... VERB the other, back-to-back constructions, and nominal constructions (Hurst and Nordlinger 2011). A range of English verbs can occur in bare reciprocal constructions (e.g., hug) (Levin 1993, p. 36), and these can also occur with overt reciprocal marking, as in (17).

17. Some friends [are] hugging each other, in greeting.

(Hurst and Nordlinger 2011, p. 77)

The English pronominal each other is the most frequent reciprocal form in English, used for almost all of the reciprocal event types in the Hurst and Nordlinger (2011) study, but used less often in chained events (where participants each act on others incrementally along a chain of actors) and radial action events (where an individual acts on other individuals). English each other is used most often for canonical reciprocal events where the participants perform an action on each other.

\subsubsection{Kriol}

Kriol is an English-lexified Creole spoken throughout the northern regions of Western Australia and the Northern Territory. Kriol likely emerged at the Roper River mission (now Ngukurr community) in the early 20th century and diffused across the northern regions of Australia (e.g., Munro 2004); creolisation processes may have taken place in other locations also (Harris 1991, p. 202). Kriol has several varieties based on geographical region, which differ primarily in lexicon and phonology (Dickson and Durantin 2019; Schultze-Berndt et al. 2013). In most varieties, reflexive and reciprocal meanings are each encoded by distinct forms, although there is some overlap (Dickson and Durantin 2019; Ponsonnet 2016). As a high-level overview, reflexive forms are related to mijelp (Sandefur 1991, pp. 91-93), from English myself, and reciprocal forms are either gija (<English together) (Sandefur 1979, p. 94) or also forms related to mijelp (Hudson 1985; Ponsonnet 2016). The form gija is found in at least some eastern Kriol varieties (Ponsonnet 2016; Schultze-Berndt et al. 2013), while variants related to mijelb express both reflexive and reciprocal functions in at least Fitzroy Valley Kriol (Hudson 1985, p. 115), a western variety. Neither reflexive nor reciprocal forms make person or number distinctions. It is not clear whether Light Warlpiri draws on one variety of Kriol more than others, although older Warlpiri speakers interacted considerably with speakers of Western varieties. An example of a Kriol reflexive form is given in (18) and of a reciprocal form in (19).

18. Wal dis hasbin en waif, dubala bin leg-i mijal. well this husband and wife 2PL PST like-TR REFL "Well this married couple, they thought highly of themselves."

(Dickson and Durantin 2019, p. 185)

\begin{tabular}{|c|c|c|c|}
\hline Mindubala & jidan & bekbon & gija \\
\hline 1PL.EXCL & sit & back & RECIP \\
\hline
\end{tabular}

(Sandefur 1979, p. 94)

A recent study of variation in reflexives across seven locations in the eastern Kriolspeaking region of the Northern Territory found that the most frequently occurring variant of the reflexive in these varieties is miyel, at least by speakers under approximately age 
40 (Dickson and Durantin 2019, p. 186). The geographical location of a speaker's home community is the main conditioning factor for the use of different forms. The variants are summarised in Table 2.

Table 2. Reflexive and reciprocal forms in documented varieties of Kriol.

\begin{tabular}{|c|c|c|c|}
\hline Variants & Location of Variety & Function & Source \\
\hline \multirow{5}{*}{ mijelp, mijelb } & \multirow{5}{*}{ Eastern and western } & reflexive & (Hudson 1985) \\
\hline & & & (Sandefur 1979) \\
\hline & & & (Munro 2004) \\
\hline & & & (Dickson and Durantin 2019) \\
\hline & & reciprocal & (Ponsonnet 2016) \\
\hline jel, self & Western & reflexive & (Hudson 1985) \\
\hline miyel, miel & Eastern & reflexive & $\begin{array}{l}\text { (Dickson and Durantin 2019) } \\
\text { (Ponsonnet 2016) }\end{array}$ \\
\hline $\begin{array}{l}\text { mel, mil, mijab, } \\
\text { miyan, mijal }\end{array}$ & Eastern & reflexive & (Dickson and Durantin 2019) \\
\hline jelp & Western & $\begin{array}{l}\text { reflexive, } \\
\text { reciprocal }\end{array}$ & $\begin{array}{c}\text { (Hudson 1985) } \\
\text { (Schultze-Berndt et al. 2013) }\end{array}$ \\
\hline \multirow[t]{2}{*}{ mijel } & Eastern & reflexive & $\begin{array}{l}\text { (Dickson and Durantin 2019) } \\
\text { (Ponsonnet 2016) }\end{array}$ \\
\hline & Western & reciprocal & $\begin{array}{l}\text { (Brown 2020, unpublished data) } \\
\text { (Schultze-Berndt et al. 2013) }\end{array}$ \\
\hline gija & Western & reciprocal & (Ponsonnet 2016) \\
\hline
\end{tabular}

Both reflexive and reciprocal forms in Kriol have most often been categorised as pronominal forms (Dickson and Durantin 2019; Hudson 1985; Sandefur 1979; SchultzeBerndt et al. 2013). They typically occur in a clause following a lexical verb. When reciprocal or reflexive pronominals are the object of a transitive verb, the transitive suffix typically remains overt, as (20)-(22) illustrate.

\section{Im=in kil-im mijelb 3SG=PST hit-TR REFL}

"He hit himself."

21. dei bin mist-im mijel

3PL PST miss-TR RECIP

"They missed each other."

East Kimberley Kriol, (20200904a AD 045, Brown 2020, unpublished data)

22. dei gibirr-im jelp mani

3PL give-TR REFL money

"They give each other money."

Fitzroy Valley Kriol, (Hudson 1985, p. 117)

However, a verbal analysis is offered for reflexives in Barunga Kriol (Ponsonnet 2016). Reflexive mijelp is categorised as a post-verbal clitic, because it occupies a post-verbal slot, does not carry primary stress, and is only found in clauses with verbs. Reciprocal gija can occur in clauses with or without verbs, and carries primary stress; it is categorised as a 'post-verbal and post-adjectival particle' and a 'nominal enclitic' (Ponsonnet 2016, p. 307). However, the data in Ponsonnet (2016) are also consistent with a pronominal categorisation of the reflexive, as both the reflexive and reciprocal forms occur in the object position following the verb. Importantly, the reflexive and reciprocal morphemes occur following the transitive marker on a transitive verb, and following a verbal iterative morpheme, -bat 'ITER', if there is one. For these reasons in this paper we consider both reflexive and reciprocal markers in Barunga Kriol to be largely pronominal, in keeping with analyses of the structure in other varieties of Kriol. 
The division of reflexive and reciprocal domains in Barunga Kriol has also recently been re-analysed (Ponsonnet 2016, p. 307). The reciprocal gija is restricted to semi-transitive reciprocal constructions, while mijelb marks both reflexives and reciprocals in transitive clauses. The exclusive adverb miself is also distinguished from the reflexive form, with the emphatic meaning of acting or being alone (Ponsonnet 2016, p. 304). It is unclear if this patterning obtains in Kriol varieties spoken elsewhere.

In sum, each of the source languages of Light Warlpiri has a different morphosyntactic strategy for the expression of reflexive and reciprocal categories. The strategies range from verbal to pronominal and are divided as to whether there is a single form for both reflexive and reciprocal categories, summarised in Table 3.

Table 3. Summary of reflexive and reciprocal structures in the source languages of Light Warlpiri.

\begin{tabular}{cccc}
\hline & Warlpiri & English & Kriol \\
\hline Same form for reflexive and reciprocal marking & $\checkmark$ & Mostly not \\
Auxiliary or verbal structure & $\checkmark$ & $\checkmark$ & $\checkmark$ \\
Distinguish person and number & & $\checkmark$ & $\checkmark$ \\
Pronominal structure & & \\
\hline
\end{tabular}

The typological differences in encoding reflexive and reciprocal expression in the source languages of the mixed language, Light Warlpiri, raise the question of how they are encoded in Light Warlpiri. The verbal structure of Light Warlpiri is largely influenced by Kriol, suggesting that reflexive and reciprocal encoding would not be drawn from the Warlpiri auxiliary; but the nominal structure of Light Warlpiri is largely from Warlpiri, suggesting that the pronominal Kriol-type structure might not fit, except that object pronouns from English and/or Kriol do occur. Alternatively, there may be a structure with attributes of both types of sources, as in Gurindji Kriol (Meakins 2011). This study examines the expression of reciprocity and reflexivity in Light Warlpiri from both structural and semantic perspectives.

\section{Methodology}

The study draws on two types of data. One type is a corpus of archived spoken data from ten adults and eight children who contributed to a cross-sectional and longitudinal naturalistic and elicited production corpus of Light Warlpiri from 2002 to 2015, called the Light Warlpiri corpus (archived at tla.org). The other is a dedicated reciprocal elicited production study conducted in 2018 and 2021, following Evans et al. (2004) and Majid et al. (2011).

\subsection{Participants}

The participants in the dedicated reciprocal elicited production study are six Light Warlpiri-speaking women in Lajamanu community, aged 17 to 25, and one Warlpirispeaking woman in the same community, aged in her fifties.

\subsection{Materials}

The elicited production data on reciprocals were collected using a series of short videos aiming to elicit reciprocal constructions (cf. Evans et al. 2004, Majid et al. 2011), because there were few tokens of reciprocals in the naturalistic corpus. The stimuli set was created so that participants could view a series of events and say what is happening in them in their own words. The 64 events showed manipulations of actors and actions shown in Table 4 (adapted examples in Appendix A). These involve the number of participants, configurations such as a pair of actors, or a chain of action, a radial configuration and so on, whether the action is performed symmetrically (each on the other) or not, and temporal organisation (simultaneous or sequential action or both). This extensional method aims to explore the range of events that can be encoded with a reciprocal construction, and allows crosslinguistic comparison. It removes a priori expectations as to which kinds of events are encoded, and how. 
Table 4. Features manipulated in event types in video stimuli.

\begin{tabular}{|c|c|c|c|c|}
\hline $\begin{array}{l}\text { Number of } \\
\text { Participants }\end{array}$ & Configuration & Symmetry & $\begin{array}{c}\text { Temporal } \\
\text { Organization }\end{array}$ & Event Type \\
\hline Two & Strong & Symmetrical & Simultaneous & Bump \\
\hline Three & Pair & Asymmetrical & Sequential & Chase \\
\hline Four & Chain & & Both & Delouse \\
\hline Five & Radial & & (Inapplicable) & Follow \\
\hline Six & Melee & & & Give \\
\hline \multirow[t]{8}{*}{ Eleven } & Ring & & & Hit \\
\hline & $(\text { Inapplicable })^{3}$ & & & Hug \\
\hline & & & & Lean \\
\hline & & & & Look \\
\hline & & & & Meet \\
\hline & & & & Be.next.to \\
\hline & & & & Shake.hand \\
\hline & & & & Talk \\
\hline
\end{tabular}

The naturalistic data consist of video and audio recordings of young children playing and talking with their friends and family members in the outside yards of their homes, from 2002 to 2005. They sometimes played with toys or picture books provided by the researcher. There are also data collected using a number of wordless picture book stimuli between 2005 and 2015 including The Monster Story (O'Shannessy 2004), the family problems picture task (San Roque et al. 2012), and the Circle of Dirt story (Eisenbeiss and McGregor 1999).

\subsection{Procedure}

For the reciprocal-elicited production task, six Light Warlpiri speakers and one Warlpiri speaker were audio-recorded in the Lajamanu Learning Centre ${ }^{4}$, alone or in the presence of other Light Warlpiri and Warlpiri speakers, respectively. (Two Light Warlpiri speakers were recorded alone, three Light Warlpiri speakers were recorded in the presence of only Light Warlpiri speakers, one was recorded in the presence of a Warlpiri speaker.) They were presented with 64 short videos of events that varied in terms of the event type, as shown in Table 4 above, in a fixed random order. Participants were asked to say what was happening in each video. Light Warlpiri speakers spoke in Light Warlpiri, and the Warlpiri speaker spoke in Warlpiri.

Naturalistic data in the Light Warlpiri corpus, transcribed using ELAN (Brugman and Russel 2004) and CLAN software, (MacWhinney 2000), were searched for tokens of reflexive and reciprocal markers, using R Studio (RStudio_Team 2020). This resulted in 103 tokens of reflexive and reciprocal markers produced by 18 Light Warlpiri speakers, adults and children, three of whom also participated in the reciprocals elicited production task. In addition, four Light Warlpiri speakers also participated in discussions about reciprocals and reflexives. In the discussions, the researcher described scenarios and asked the speaker what she would say in the scenario, if she hears people say a specific construction, or if she says a construction. Each speaker was asked to produce each construction herself.

The semantics of the reciprocal forms were analyzed following Majid et al. (2011), with a binary coding of the features tailored to the events in the reciprocal stimuli videos, specifically symmetry, temporal organization, and the configuration of the action amongst participants, as explained above.

Auditory impressionistic analysis of the reflex of the word-final English-derived /f/ phone of Light Warlpiri reciprocal tokens from four speakers was undertaken to test for their realisation as a bilabial stop or labio-dental fricative. Using Praat (Boersma 2001) a spectrogram for each reciprocal token was visually inspected by the two authors independently. A phone was labelled a stop if there was a period of low intensity with no

3 The label 'inapplicable' applies to asymmetrical events, where only one actor acts on the other. (Adapted from Majid et al. (2011)).

4 Run by the Batchelor Institute of Indigenous Tertiary Education and the Warlpiri Education Training and Trust. 
high-frequency noise, followed by a vertical bar indicating a stop release. A phone was labelled a fricative if there was a period of sustained high-frequency energy. There was agreement on $95 \%$ of tokens, with the conclusion that the English-derived element $/ \mathrm{f} /$ is realised as a stop in reciprocal marking in Light Warlpiri ${ }^{5}$.

\section{Encoding of Reflexivity and Reciprocity in Light Warlpiri}

The source languages of Light Warlpiri encode reflexivity and reciprocity in different ways-English and Kriol use pronominal forms, and for the most part, have different forms for reflexives versus reciprocals. Warlpiri uses a single clitic in the auxiliary to express both types of events. How do these play out in Light Warlpiri? The structural encoding of reflexives and reciprocals in Light Warlpiri is described first, followed by semantic scope.

\subsection{Structural Encoding: Light Warlpiri}

Light Warlpiri uses a single form for both reflexive and reciprocal expressions. The form is an affix -selp, derived from English -self. The affix attaches to English- and/or Kriolderived pronominal subject forms for each person and number, forming the construction PRO-REFL/RECIP. The pronominal forms agree with the clausal subject, which need not be overtly expressed in the clause. The weak pronominal forms for 2nd (yu, yumob) and 3rd person $(i, d e(m))$, are the same as those in non-coreferential clauses. The 1st person form, mai '1SG.POSS' also occurs as a possessive, but the 1st person form au '1PL.POSS' does not usually occur in Light Warlpiri. This suggests that there is a reflexive-reciprocal unit comprised of PRO-REFL/RECIP. The phonetic realisation of the final consonant in -selp is a bilabial plosive [p], represented orthographically here as ' $p$ '. The vowel quality was not analysed for this study; it appears to be in the range from a low front to mid-front vowel, $/ æ /$ to $/ \varepsilon /$.

The PRO-REFL/RECIP complex occurs within a verbal word. Evidence for this is that it occurs between the lexical verb stem (with or without progressive and/or transitive marking) and the verbal iterative affix - pat 'ITER', derived from Kriol -bat 'ITER'. The orthographic representation of -pat is due to the auditory impression that the initial consonant is a voiceless plosive, supported by inspection of several tokens in Praat (Boersma 2001). There is a single example in the corpus of a reflexive marker following iterative -pat, in (23). It is not clear whether it represents a switch to Kriol or is a possible construction in Light Warlpiri. Other Light Warlpiri speakers did not replicate the structure in discussions, so we conclude that this is not a stable structure in Light Warlpiri.

$\begin{array}{llll}\text { 23. de } & \text { kliin-im-pat } & \text { de-selp } & \text { na } \\ \text { 3PL } & \text { clean-TR-ITER } & \text { 3PL-REFL } & \text { DIS }\end{array}$

'They're cleaning themselves now.'

(LAC58_CircleOfDirt)

Examples of reflexive marking are given in (24) and (25), and of reciprocal marking in (26) and (27).

24. $\mathrm{a}=\mathrm{m} \quad$ wash-mai-selp-pat ngapa-nga

1SG=NFUT wash-1SG-REFL-ITER water-LOC

"I washed and washed myself in the water."

(Elicit_LA21_2020)

$\begin{array}{lllll}\text { 25. } & \mathrm{i}=\mathrm{m} & \text { puk-im-i-selp-pat } & \text { every } & \text { minute } \\ \text { 3SG=NFUT } & \begin{array}{l}\text { noke-TR-3SG-REFL- } \\ \text { ITER }\end{array} & \text { every } & \text { minute } & \text { needle-COM-ERG }\end{array}$

"She poked herself over and over with the needle."

(Elicit_LA21_2020)

\footnotetext{
Hendy (2019) shows that the Light Warlpiri phonemic inventory includes the English-derived fricative phoneme /f/. The statement here is that in reflexive-reciprocal -selp it is lexicalised as a stop realisation.
} 
$\begin{array}{lll}\text { 26. } & \text { nyampu-rra-ng } & \mathrm{de}=\mathrm{m} \\ \text { DIS } & \text { DEM-PL-ERG } & \text { 3PL=NFUT }\end{array}$

"Ah these, they are slapping each other."

slap-3PL-RECIP-ITER

(Recip_LAC58)

27. a $\begin{array}{llll}\text { a } & \mathrm{de}=\mathrm{m} & \text { jis } & \text { gib-de-selp-pat } \\ \text { DIS } & \text { 3PL=NFUT } & \text { just } & \text { give-3PL-RECIP-ITER } \\ \text { "Ah they are just giving } & \text { each other everything." }\end{array}$ everything

(Recip_LAC58)

The reflexive-reciprocal affix can also occur following a progressive marker derived from English -ing 'PROG', as in (28).

28. Nyampu-rra-ng de slap-ing-de-selp-pat

DEM-PL-ERG 3PL slap-PROG-3PL-RECIP-ITER

"These are slapping each other."

(Recip_LAC58)

The construction of reflexive-reciprocal $P R O$-selp occurring between a lexical verb stem and aspectual -pat raises a question of the status of -pat in Light Warlpiri. In Kriol, -bat functions as an aspectual marker, associated with continuous and iterative actions (Hudson 1985, p. 40; Schultze-Berndt et al. 2013, p. 7), and of plural participants (Hudson 1985, pp. 39-40). In the Light Warlpiri data, the affix -pat only occurs on verbs, not in any position that could be construed as nominal, and does not have other nominal properties, for instance, hosting nominal affixes. The affix -pat is present in events where an action is performed repeatedly and sequentially, often by more than one actor, and for most speakers, involves more than two participants in the event. While not all repeated, sequential actions with plural participants are encoded with aspectual -pat, only two instances of -pat out of 19 occurrences encode a non-repetitive, non-sequential action with fewer than three participants, and the event in both instances is one of continuous 'leaning', where two people lean against each other, back-to-back (see the image in Appendix A). This is in line with a link between iterativity and continuity. In conclusion, -pat is a verbal aspectual affix indicating iterative, continuous actions and/or plural participants, glossed as -pat 'ITERATIVE'.

In terms of prosody, impressionistically the main stress in the verbal word occurs on the first and last syllables, i.e., on the first syllable of the lexical stem and on iterative -pat, if present. When iterative -pat is not present the main stress is on the first syllable. Iterative -pat appears to be realised with relatively long vowel duration and relatively greater amplitude. This supports the analysis of a multimorphemic verbal word, perhaps with an emphasis on the peripheral syllables as word boundaries. However, an acoustic analysis of prosody remains for future work.

Although the verbal construction with -pat present provides evidence of the verbal nature of reciprocal and reflexive marking, the constructions with occurrences of -pat account for only $12 \%$ of the instances of the morphological reflexive-reciprocal. Examples of reflexive marking for each person and number where -pat is not present are given in (29-34), and of reciprocal marking in (35-37).

$\begin{array}{llll}\text { 29. } & \mathrm{A}=\mathrm{m} & \text { puk-mai-selp } & \text { niidil-kurlu-ng } \\ \text { 1SG=NFUT } & \text { poke-1SG-REFL } & \text { needle-COM-ERG } \\ \text { “I poked myself with a needle." } & \end{array}$

(Elicit_LA21_2020)

30. wi meik-au-selp fal-dan jalpi

1PL make-1PL-REFL fall-down self

"We make ourselves fall down, on our own." 
Interestingly, example (30) shows the use of a different form also derived from English 'self', jalpi 'self', but the meaning is not reflexive. The meaning of jalpi 'self' is that of 'by one's self' or 'on one's own/alone'. All of the instances of jalpi in the data have this meaning, and are distinct in pronunciation and surrounding morphosyntactic structure from the reflexive-reciprocal affix -selp.

31. ngaka-jala yu garra later-EMPH 2SG FUT see-2SG-REFL

"You'll see yourself on the video later."

nganayi vidia-ngka something video-LOC

$\left(\mathrm{CO} 2 \_8 \mathrm{a}\right)$

32. go swim meik-yumob-selp fresh

go swim make-2PL-REFL fresh

"Go and swim and refresh yourselves."

(Elicit_LAC10_2020)

(2008ERGstory_LA62)

In transitive sentences, the reflexive pronominal expression attaches to the verb stem, and an allomorph of the transitive marker, -im 'TRANS' is not present. There is a single occurrence of a reflexive form occurring independently of a pronoun, as part of a prepositional phrase headed by the English-derived preposition, with, as in (34), however, this may be an instance of a slip-of-the-tongue type error.

\begin{tabular}{|c|c|c|c|c|c|}
\hline $\begin{array}{l}\mathrm{de}=\mathrm{m} \\
3 \mathrm{PL}=\mathrm{NFUT}\end{array}$ & $\begin{array}{l}\text { get } \\
\text { INCHO }\end{array}$ & $\begin{array}{l}\text { api } \\
\text { happy }\end{array}$ & $\begin{array}{l}\text { with } \\
\text { with }\end{array}$ & $\begin{array}{l}\text { selp } \\
\text { reflex }\end{array}$ & $\begin{array}{l}\text { na } \\
\text { DIS }\end{array}$ \\
\hline
\end{tabular}

(2008ERGstoryLA62)

Examples of reciprocal marking for each person and number are given in (35)-(37). 35.

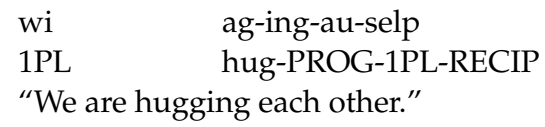

(Elicit_LAC10_2020)

$$
\text { mayi }
$$$$
\text { Q }
$$

Example (36) shows that, as with reflexives, the reciprocal expression attaches to the verb stem, and the transitive marker allomorph, -im 'TR' is not present.

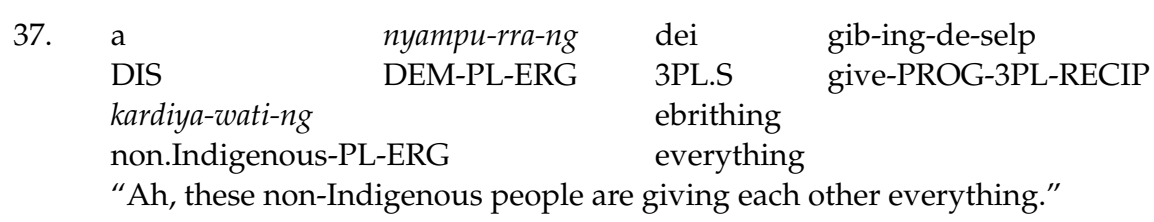

(Recip_LAC58)

The reflexive-reciprocal affix can occur following a progressive marker derived from English -ing 'PROG', as in (35) and (37). If the progressive verb is transitive, transitive -it attaches to -ing, and the reflexive-reciprocal follows, as in (38). There are no instances of -ing following the reciprocal in the data. The pronoun dei '3PL.S' in (37) is a pronominal allomorph that occurs when there is no overt TMA marking in the auxiliary, and the verb is marked with a progressive affix. Reflexive-reciprocal marking does not change the valency 
of the verb, as shown in (37), where the transitive subject argument nyampu-rra 'DEM-PL' is marked with an ergative case-marker.

There are three instances in the data of English each other, from two speakers, suggesting that this is possible, but not the conventional expression of reciprocals. It is not clear if this should be categorised as a switch to English or as Light Warlpiri. For this reason, this encoding is not discussed further here.

Reflexive and Reciprocal Encoding for Dative Arguments

In a clause with two nonsubject arguments, the reflexive-reciprocal element can follow a dative affix, as in (38).

38. De

3PL pass-PROG-TR-DAT-3LP-RECIP-ITER

'They're passing it to each other.'

(Recip_LAC41)

Dative bo 'DAT' is derived from English 'for' in word-shape, and combines with Warlpiri dative semantics to function as a dative marker, that can be glossed in English as 'to, for' (cf. O'Shannessy 2016). Five of the six speakers produce the dative construction, and they account for $15 \%$ of expressions of reciprocal events in the data. Only one speaker produced a verb like that in example (38), where both dative and iterative affixes are present. Dative $b o$ 'DAT' has previously been documented as being external to the verb (O'Shannessy 2016, p. 89), but new data in this paper, in (38), show that it is internal to the verb, as it occurs between the verbal transitive marker and reflexive-reciprocal affix, which in turn occurs before the iterative affix. A dative element occurring within a verb complex suggests the influence of Warlpiri, where dative cases can be marked both in the auxiliary and on NPs. For instance, in a Warlpiri clause with the verb, wangka- 'talk, speak', the dative case is registered in the auxiliary and on the overt nonsubject nominal, as in example (39).

$\begin{array}{llll}\text { 39. wati } & k a=r l a & \text { wangka-mi } & \text { nyanungu-parnta-ku } \\ \text { man } & \text { PRES=DAT } & \text { speak-NPST } & \text { 3SG-partner-DAT }\end{array}$

(2010ERGstory_YWA04)

Events for which speakers use a dative affix in Light Warlpiri are encoded either by verbs whose translational equivalents in Warlpiri select a dative nonsubject argument, or by dative-marked nominals.

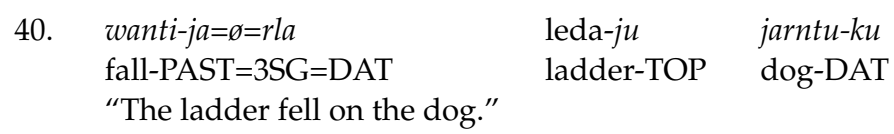

(O’Shannessy 2016, p. 89)

Example (40), in which the dative case appears in an adjunct construction in Warlpiri, illustrates that in the phonological realisation the dative appears to attach directly to the verb. In Warlpiri, this occurs when the auxiliary pronominal affix has no phonological realisation, because the verb form is past tense and the grammatical subject is third person singular. We speculate that this may have influenced the Light Warlpiri structure of a dative element occurring in the verb.

In Light Warlpiri, tok 'talk, speak' takes a dative nonsubject argument, under influence from Warlpiri (cf. O'Shannessy 2016). Other Light Warlpiri verbs that select a dative nonsubject argument include ditransitive verbs, e.g., 'give', and 'pass', as in 'pass $x$ to $y^{\prime}$, and an inchoative verb get 'INCHO' modeled on Warlpiri.

An example of dative marking both within the verb and on a nominal in Light Warlpiri is given in example (41). In (41) the English-derived verb get 'INCHOATIVE' 
shows Warlpiri-derived inchoative meaning, under influence from a Warlpiri structure involving a pre-verbal element and an inchoative inflecting verb, -jarrimi ' $\mathrm{INCHO}$ '.
41. De get-bo-de api olot-ik-juk
3PL INCHO-DAT-3PL happy whole.lot-DAT-yet
"They become happy with themselves/each other." (LIT: 'they become-for-them happy whole.lot-for-yet')

(Recip_LAC04)

A reflexive-reciprocal marker is not obligatory when expressing a reflexive-reciprocal event. The object pronoun dem '3PL.O', also in a contracted form, de '3PL.O', attached to the dative marker but without a morphological reciprocal affix, is used by three speakers to refer to reciprocal events, as in (42). This type of construction accounts for $3.7 \%$ of encodings of reciprocal events.
42. de $=\mathrm{m}$ gib-bo-de rdaka jirrama-ng
3PL=NFUT give-DAT-3PL hand two-ERG
"They give each other a handshake." (LIT: 'they give-for-them hand two-ERG')

(Recip_LAC04)

The encodings of reflexivity and reciprocity in Light Warlpiri are summarised in Table 5.

Table 5. Encoding of reflexivity and reciprocity in Light Warlpiri.

\begin{tabular}{ccc}
\hline Person and Number & Form & Structure \\
\hline & & VERB(- \\
1SG & mai-selp & PROG)(TR)(PART)(DAT)+ \\
2SG & yu-selp & -1SG-REFL/RECIP(-ITER) \\
3SG & i(m)-selp & -2SG-REFL/RECIP(-ITER) \\
1PL & au-selp & - - PL-REFL/RECIP(-ITER) \\
2PL & yumob-selp & -2 PL-REFL/RECIP(-ITER) \\
3PL & de(m)(-selp) & -3 PL(-REFL/RECIP)(-ITER) \\
& ? with ø-selp & \\
& ? each other & \\
\hline
\end{tabular}

\subsection{Structural Encoding: Warlpiri Reciprocal Forms}

Although the polysemous reflexive-reciprocal form in Warlpiri is well documented, reciprocal elicitation data for Warlpiri were collected from one speaker using the same set of stimuli as used with Light Warlpiri, which provides a useful and contemporary point of comparison between the two languages. The Warlpiri speaker's data conform with the previous literature about Warlpiri in terms of structure, with the clitic =nyanu, also now pronounced as =nyan, as the reflexive-reciprocal form (see Section 5). Examples (43) and (44) provide examples of the reciprocal as expressed in Warlpiri spoken in Lajamanu community by one speaker.
43. japi-manu=pala=nyan jirrama-ngku-ju swap-CAUS=DUAL=RECIP two-ERG-TOP
"The two of them swapped with each other."

(RECIP_WA56)
44. nyampu jirrama-kari-ng ka=pala=nyanu yi-nyi rdaka DEM two-other-ERG PRES=DUAL=RECIP give-NPST hand "Here another two shake hands with each other." (LIT: 'here two-other each.other give hand')

\footnotetext{
6 The symbol '?' indicates that these constructions are likely not conventionalised in Light Warlpiri.
} 


\subsection{Semantic Encoding of Reciprocity in Light Warlpiri and Warlpiri}

The reciprocals elicited production task was undertaken by six Light Warlpiri speakers and one Warlpiri speaker (and the Warlpiri speaker is not a speaker of Light Warlpiri). There is both variation and agreement across speakers in terms of the semantics of events that are encoded using a reciprocal construction. Some reciprocal events elicited responses from some speakers that did not include the reciprocal affix, -selp, so the construction with -selp is here called a morphological reciprocal construction. Statistical analyses are not run on the data because of the small number of tokens, yet the numbers are sufficient to identify tendencies in how speakers encode the events.

The events that elicited the most tokens of morphologically reciprocal constructions are those categorised as strong, which includes symmetrical action. Strong events account for $48 \%(n=76)$ of all reciprocal responses in Light Warlpiri and for $70 \%(n=16)$ of them in Warlpiri. Strong simultaneous events elicited more morphological reciprocal expressions than strong sequential events did. For all other types of events, the responses are spread fairly evenly in Light Warlpiri, less so in Warlpiri. In Light Warlpiri chain events received the next most responses with a morphological reciprocal $(13 \%, n=21)$, while in Warlpiri pair and radial events did ( $9 \%$ each, $n=2$ (pair), $n=3$ (radial)). The percentages of event types that received morphological reciprocal responses in Light Warlpiri and Warlpiri are summarised in Figure 1.

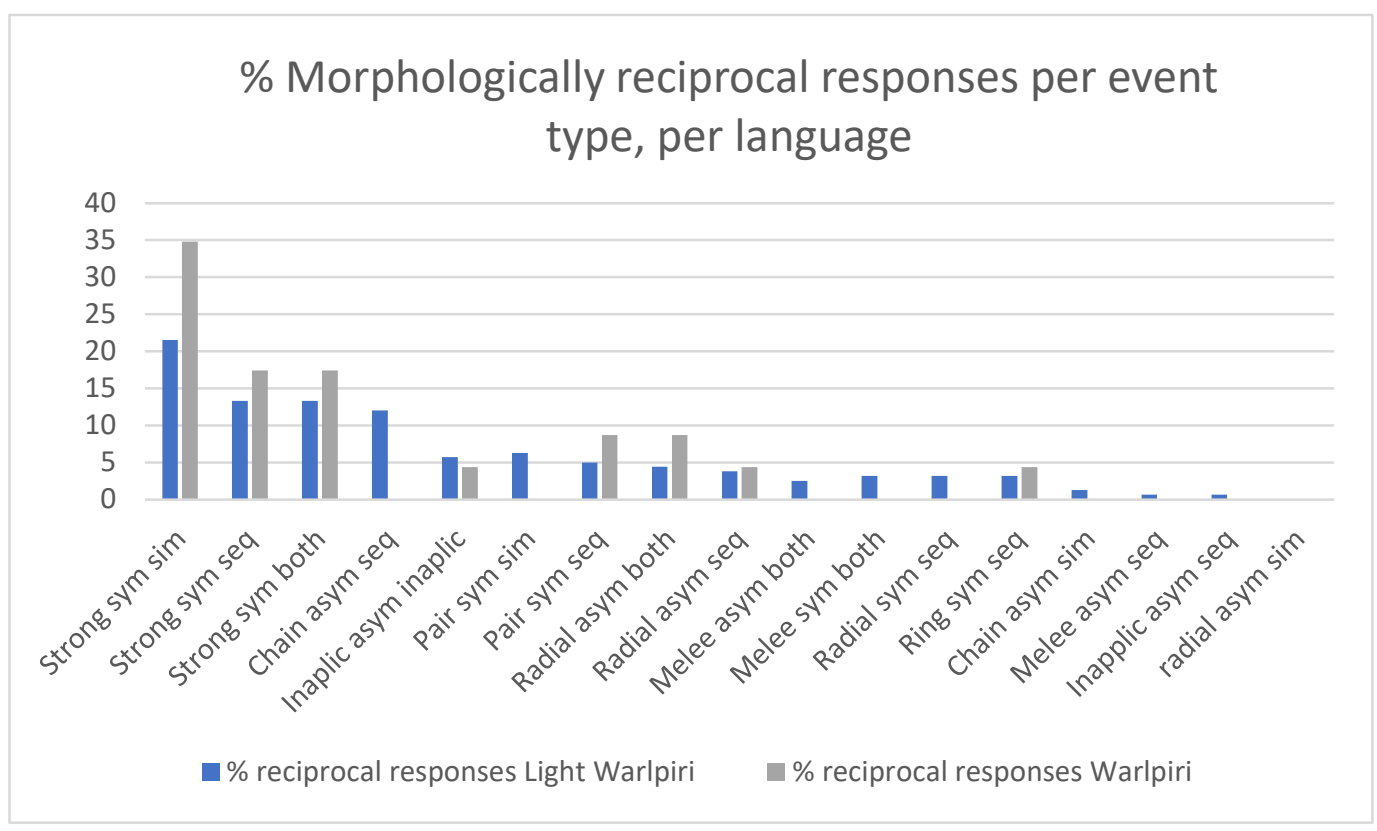

Figure 1. Percent of morphologically reciprocal responses per event type, of all reciprocal responses, per language.

The responses in Light Warlpiri show considerable individual variation, with five speakers along a cline of how often an event receives a reciprocal expression, and one speaker using morphological reciprocal expressions much less often than the others (see Figure 2). This speaker also produced more dative expressions without a morphological reciprocal marker than other speakers did, e.g., bo $\mathrm{de}(m)$ 'DAT 3PL', as in example (42) above. The speaker who diverges from the others produced only $4 \%$ of all morphologically reciprocal responses in Light Warlpiri, and the other five speakers each produced between $16-26 \%$ of responses. The number of morphologically reciprocal responses for these five speakers ranges from 25 to 42 responses each. For comparison, the Warlpiri speaker produced 26 responses using the morphological reciprocal marker. All six Light Warlpiri speakers have lived in the Lajamanu community all of their lives, but the speaker with divergent patterning has spent more time visiting the major centre, Darwin, than the other 
speakers have, and therefore has had more exposure to ways of talking other than Warlpiri and Light Warlpiri. It is hypothesised that this may be the reason for the difference, but there may be other sociolinguistically motivated reasons unknown to the authors.

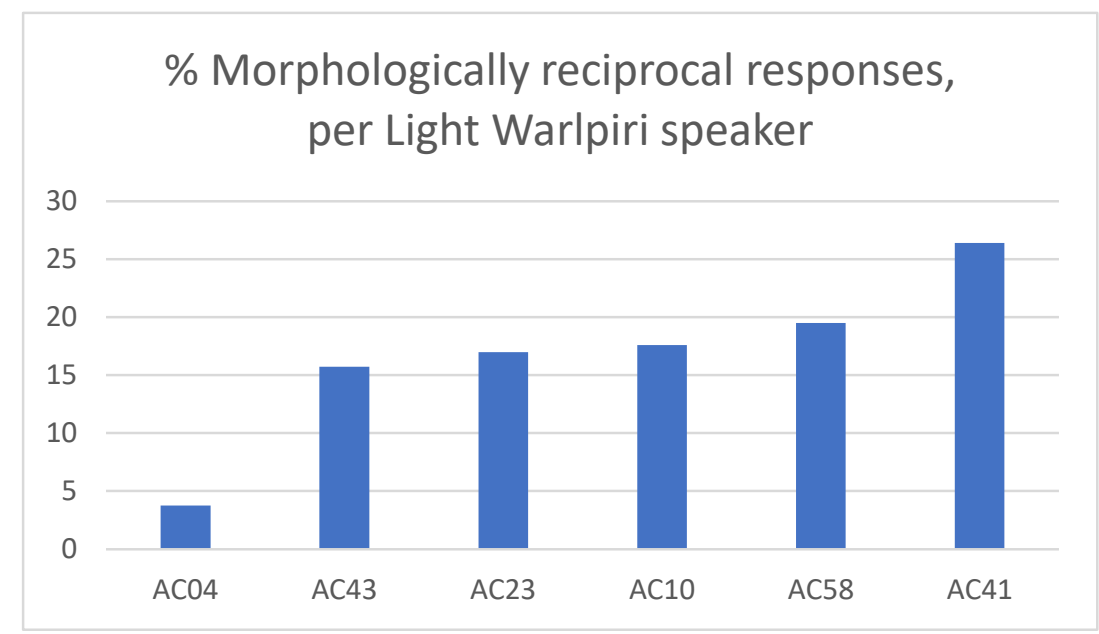

Figure 2. Percent of all morphologically reciprocal responses, per Light Warlpiri speaker.

The clearest agreement across speakers is seen when an event is not encoded with a morphological reciprocal. Fourteen events were not encoded with a morphological reciprocal by any speaker, either in Light Warlpiri or Warlpiri. Of these, twelve involve asymmetrical actions, and ten do not involve simultaneous actions. Seven are events in which one person acts on another but the action is not reciprocated.

\section{Discussion}

\subsection{Structural Encoding of Reflexive and Reciprocal Events in Light Warlpiri}

Reflexive-reciprocal expressions in Light Warlpiri are encoded in verbal constructions. An affix -selp attaches to a pronominal morpheme derived from English and/or Kriol. The evidence for the verbal construction is that the reflexive-reciprocal affix occurs in the verbal word before the final affix, iterative -pat 'ITER', as in examples (24)-(28).

The encoding shows clear influences from two of the three source languages, Warlpiri and English. The word-shape of -selp is derived from the English reflexive -self. The reflexive-reciprocal complex is English-like in that the pronominal forms distinguish person and number, as in English reflexive expressions. However, unlike in English, in Light Warlpiri, the same forms also encode reciprocal expressions, and accordingly attach to pronominal forms for each person and number. The use of the same form to encode both reflexives and reciprocals shows the influence of Warlpiri, where there is a single reflexive-reciprocal form =nyanu 'REFL/RECIP', and perhaps of Western varieties of Kriol, where there is also a single form for both reflexives and reciprocals. Grammaticalisation chains of reflexive-to-reciprocal meaning are well attested cross-linguistically (Heine and Miyashita 2008). This may help to explain the reflexive-reciprocal morphosyntax in Light Warlpiri, as the English-derived dedicated reflexive marker is used for both reflexives and reciprocals in Light Warlpiri, showing a similar reflexive-to-reciprocal movement.

The Light Warlpiri structure of VERB-(PROG)-(TR)-(PART)-(DAT)-(PRO-RECIP)(ITER) shows that reciprocal encoding is structurally verbal. The influence of Warlpiri is perhaps seen in the multimorphemic verbal construction that includes reflexive-reciprocal encoding. The influence may be that (a) in Warlpiri the reflexive-reciprocal marker occurs in the auxiliary, as opposed to occurring in a separate nominal or pronominal phrase, and (b) Warlpiri has agglutinative structure, and this may influence the occurrence of a multimorphemic verb. The structure of reflexive-reciprocal expression in Light Warlpiri, then, draws mostly on Warlpiri and English, but is not a structural copy of any single 
source language. Table 6 shows how the reflexive-reciprocal structures in Light Warlpiri are influenced by its source languages.

Table 6. Comparison of reflexive and reciprocal structures in Light Warlpiri and its source languages, Warlpiri, English and Kriol.

\begin{tabular}{ccccc}
\hline & Light Warlpiri & Warlpiri & English & Kriol \\
\hline Same forms for reflexive and reciprocal marking & $\checkmark$ & $\checkmark$ & Yes and no \\
Auxiliary or verbal structure & $\checkmark$ & $\checkmark$ & $\checkmark$ & $\checkmark$ \\
Distinguish person and number & $\checkmark$ & & $\checkmark$ \\
Pronominal structure & & & $\checkmark$ \\
\hline
\end{tabular}

The data suggest that Light Warlpiri has a verb structure with core and optional segments. The core segments are AUX-PRO and the verb stem. Clause structure when two core arguments are overt is (NP) AUX VERB (NP), where an NP either preceding or following a verb may be a subject or nonsubject NP, as in Table 7.

Table 7. Clause structure of Light Warlpiri.

\begin{tabular}{|c|c|c|c|c|}
\hline Line No. & Optional NP(-ERG) * & AUX & Verb & Optional NP(-ERG) * \\
\hline 1 & $\begin{array}{c}\text { kurdu-kurdu-ng } \\
\text { child-REDUP-ERG }\end{array}$ & $\begin{array}{c}\mathrm{de}=\mathrm{m} \\
\text { 3PL }=\mathrm{NFUT}\end{array}$ & $\begin{array}{l}\text { jeis-im-dem } \\
\text { chase-TR-3PL }\end{array}$ & $\begin{array}{l}\text { nyanungu-rra } \\
\text { 3SG-PL }\end{array}$ \\
\hline 2 & & $\begin{array}{c}\text { de } \\
\text { 3PL }\end{array}$ & $\begin{array}{c}\text { old-ing-de-selp } \\
\text { hold-PROG-3PL-RECIP }\end{array}$ & $\begin{array}{l}\text { al-da kayinga-wati-ng } \\
\text { all-DEM-friend-PL-ERG }\end{array}$ \\
\hline 3 & $\begin{array}{l}\text { dat jarntu-ng } \\
\text { DEM dog-ERG }\end{array}$ & $\begin{aligned} \mathrm{i} & =\mathrm{m} \\
3 \mathrm{SG} & =\mathrm{NFUT}\end{aligned}$ & $\begin{array}{l}\text { luk-dem-pat } \\
\text { look-3PL-ITER }\end{array}$ & $\begin{array}{l}\text { kurdu-kurdu } \\
\text { child-REDUP }\end{array}$ \\
\hline
\end{tabular}

${ }^{*}$ An NP occurring before or after the AUX + VERB complex may be either a subject or nonsubject NP. Only a subject NP is marked with ergative case-marking.

Table 8 shows the structure of the verb complex, including the auxiliary and the verb, with reflexive-reciprocal forms shown for 3PL arguments only.

Table 8. Structure of Light Warlpiri verbs.

\begin{tabular}{|c|c|c|c|c|c|c|c|c|c|}
\hline Line No. & Aux Pro & Aux TMA & Verb Stem & Prog & $\operatorname{Tr}$ & Part & Dat & NonSubj Pro/Recip-Reflex & Iter \\
\hline 1 & de & & pass & ing & it & & bo & deselp & pat \\
\hline 2 & de & & gib & ing & & & & deselp & pat \\
\hline 3 & de & $\mathrm{m}$ & tok & & & & bo & deselp & \\
\hline 4 & de & & luk & ing & & raun & bo & deselp & \\
\hline 5 & de & $\mathrm{m}$ & jeis & & $\mathrm{im}$ & & & dem & \\
\hline 6 & $\mathrm{i}$ & $\mathrm{m}$ & luk & & & & & dem & pat \\
\hline 7 & i & $\mathrm{m}$ & jeis & ing & & & & dem & pat \\
\hline 8 & de & $\mathrm{m}$ & gib & & $\mathrm{im}$ & & bo & dem & \\
\hline 9 & de & $\mathrm{m}$ & teik & & $\mathrm{im}$ & & & im & \\
\hline 10 & de & & $\mathrm{ag}$ & ing & it & & & & \\
\hline
\end{tabular}

Table 8 shows examples of auxiliary and verb structure with morphemes aligned to illustrate their relative positions. The table shows that the Light Warlpiri reflexivereciprocal unit occurs in the position of nonsubject pronouns within the verbal word, that is, it is part of the paradigm of nonsubject bound, or weak, pronouns (lines 1-4). This aspect of the structure somewhat echoes that of Warlpiri, where the reflexive-reciprocal clitic occurs in the nonsubject bound pronoun paradigm of the auxiliary (Laughren Forthcoming), but in Light Warlpiri, it is not within the auxiliary. 
The Light Warlpiri reflexive-reciprocal complex can co-occur with transitive marking on a progressive-marked verb (VERB-ing-it), as in example (38), but does not co-occur with a transitive marker on a non-progressive verb (VERB-im), seen in (36). In this way, the Light Warlpiri construction again differs from reflexive and reciprocal constructions in Kriol, as in Kriol the transitive marker on the verb most frequently remains overt when a pronominal reflexive-reciprocal is present in the clause (Hudson 1985, p. 117; Ponsonnet 2016; Sandefur 1979, p. 94).

The use of bo 'DAT' in Light Warlpiri, as in example (38), shows Warlpiri dative semantics overlayed onto an English-derived word shape, as seen in non-coreferential constructions with verbs that take a dative nonsubject argument, where the English-derived preposition bo 'DAT' takes on the semantics of the Warlpiri dative (O'Shannessy 2016). In a reflexive-reciprocal construction the Warlpiri-influenced dative semantics are still present, but the dative form occurs within the verb, as in lines 1, 3, 4 and 8 in Table 8 . Another link to the use of a dative construction for a coreferential expression is that in Warlpiri the reflexive-reciprocal clitic can indicate coreference between a subject argument and a dative (adjunct) nonsubject argument, and in some contexts, the argument is marked with a dative affix, as in example (10) in Section 3.3.

The influence of English and Warlpiri, more than of Kriol, in the reflexive-reciprocal domain in Light Warlpiri is especially interesting in terms of the contributions of source languages to a mixed language. Most documented mixed languages show the influence of two source languages, but in Light Warlpiri the discrete influence of each of the three source languages is clear. The contribution of English is especially clear in the expression of reflexive and reciprocal events, where the English distinctions of person and number in reflexives are seen in Light Warlpiri, and extended to reciprocals. Similarly, the influence of Warlpiri in having a single verbal form for both functions is clear, and is perhaps also seen in the multimorphemic verb.

There are four interesting implications of this in terms of the structure of mixed languages. One is that a mixed language can have distinct contributions from three languages. The three languages, however, can be grouped in terms of some similarityEnglish and Kriol, while completely separate languages, are both English-lexified, and both relatively isolating in type. Relevant to this paper, they both encode reflexives and reciprocals pronominally, and with separate forms for reflexives versus reciprocals. Warlpiri, by contrast, is an agglutinating language, and encodes reflexives and reciprocals with a single form in the auxiliary. There is, therefore, in a sense a two-way division of some categories within this domain. The two-way division mirrors that of ancestral language (Warlpiri) and newer languages of wider social utility (English and Kriol).

Second is that one domain, e.g., reflexives-reciprocals, can show a different weighting of contributions from source languages than another domain. The Light Warlpiri auxiliary and verbal transitivity marking show influences from Warlpiri, English and Kriol, with a prominent contribution from Kriol, whereas the reflexive-reciprocal domain shows much more influence from English and Warlpiri and much less from Kriol.

Thirdly, the reflexive-reciprocal domain combines the features of the source languages in a way that incorporates a near-maximal number of distinctions. It incorporates all of the distinctions of person and number from English reflexives, and extends these to reciprocals. It is difficult to say if including a single English reciprocal form 'each other', would be more complex. A near-maximal combination is also seen in the phonological system of Light Warlpiri, where the plosive series shows the near-maximal incorporation of voicing and place of articulation distinctions from the source languages (Bundgaard-Nielsen and O'Shannessy 2021).

Fourth, reflexive-reciprocal encoding adds morphological complexity to the verbal word, by including the dative and reflexive-reciprocal affixes in verbal structure. This is unlike the isolating structures of English and Kriol, and more like the agglutinative structure of Warlpiri. 


\subsection{Semantic Encoding}

The responses to the stimuli in Light Warlpiri show both agreement and variation across speakers. The agreement in when to use, and when not to use, morphological reciprocal encoding suggests that in both Light Warlpiri and Warlpiri events are more likely to be encoded with a morphological reciprocal marker when they involve symmetrical, simultaneous action, and strong reciprocal events, where each participant acts on each other participant in the event. These are features of semantically prototypical reciprocal events. This distribution of the use of a reciprocal construction is comparable to that of English. In Warlpiri, Light Warlpiri and English, strong, symmetric, simultaneous and sequential events produced more reciprocal constructions, and chain and radial events elicited fewer. Here the influences of Warlpiri and English semantics align, and accordingly, Light Warlpiri aligns with both of them.

\section{Conclusions}

The source languages of the mixed language, Light Warlpiri, have different structural means for encoding reflexivity and reciprocity. Warlpiri uses an auxiliary clitic for both reflexive and reciprocal expression, while English and Kriol both use pronominal forms, and most often have one form for reflexives and another for reciprocals (with some variation between Kriol varieties). English distinguishes person and number in reflexives, but not in reciprocals; the other two source languages do not distinguish person or number in either.

In Light Warlpiri, these strategies are combined into a system that echoes, but is not identical to, any of the sources, and presents a near-maximal number of source language distinctions. Light Warlpiri draws on the English system in using English-derived reflexive word shapes attached to pronouns, distinguishing person and number, and extends these to reciprocals. It draws on Warlpiri in using the same forms for reflexives and reciprocals. It also draws on Warlpiri in that the verb is multimorphemic, seen in the verbal structures that also contain an iterative marker, as the reflexive-reciprocal occurs between the lexical verb stem and the iterative marker.

The reflexive-reciprocal system of Light Warlpiri has interesting implications for the possible structures of mixed languages. One, it provides clear evidence that a mixed language can combine elements of three source languages, in this case, Warlpiri, English and Kriol. However, the three languages can in some ways be grouped into two typesEnglish and Kriol are both English-lexified, relatively isolating in structure and show some similarity in the way they encode reflexives and reciprocals; on the other hand, Warlpiri has an agglutinating structure and encodes reflexives and reciprocals differently from English and Kriol.

Second, it shows that the source languages can influence the subsystems of a mixed language to different degrees. In the Light Warlpiri reflexive-reciprocal system English and Warlpiri show the greatest contributions, while in some other areas of grammar English shows less influence.

Third, the reflexive-reciprocal domain combines the features of the source languages in such a way as to incorporate a near-maximal number of source distinctions. It incorporates all of the distinctions of person and number from English reflexives, and extends these to reciprocals.

Fourth, although the word-shapes of the morphemes draw on English and Kriol, they are included in verb structure, which is unlike the isolating structures of English and Kriol, and more like the agglutinative structure of Warlpiri.

Author Contributions: The study was conceptualised by C.O., who also collected the data. C.O. and C.B. transcribed and analysed the data, and drafted and wrote the paper. The project was administered by C.O., who secured the funds. Both authors have read and agreed to the published version of the manuscript. 
Funding: The project was funded by a National Science Foundation Grant \#1348013, the (Australian Research Council) ARC Centre of Excellence for the Dynamics of Language and an ARC Future Fellowship FT190100243 awarded to O'Shannessy.

Institutional Review Board Statement: The study was conducted according to the guidelines of the Declaration of Helsinki, and approved by the Institutional Review Board (or Ethics Committee) of the University of Michigan (HUM00020003, 12 May 2014) and Australian National University (2015/222, 24 April 2015).

Informed Consent Statement: Informed consent was obtained from all subjects involved in the study.

Data Availability Statement: De-identified data are archived at The Language Archive, tla.org.

Acknowledgments: We thank the speakers and members of Lajamanu community, and the funding bodies. For insights into the analysis, we thank the anonymous reviewers, and Jane Simpson and Denise Angelo.

Conflicts of Interest: The authors declare no conflict of interest.

\section{Appendix A}

Adapted extracts from the reciprocal elicitation task (Evans et al. 2004; Majid et al. 2011) with representative Light Warlpiri responses. The videos used were in colour.

Appendix A.1. Responses to Item 12: Lean Against

Number of participants: 2

Configuration: strong

Symmetry: symmetrical

Temporal organization: simultaneous

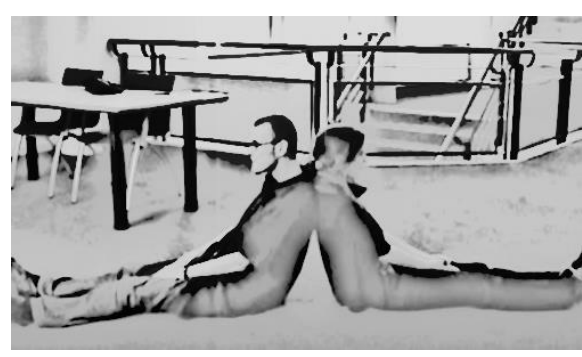

1. dei lean-ing-de-selp-pat

3PL lean-PROG-3PL-RECIP-ITER

"They are leaning against other."

(Recip_LAC04)

2. an nуатри dei lean-ing-bo-de-selp

and DEM 3PL lean-PROG-DAT-3PL-RECIP

pu- purturlu- dis nganayi karnta an wati

purturlu-kurra purturlu

"And there they are leaning against each other, back to back you know, this woman and man."

(Recip_LAC58)

3. dei lean-ing-bo-de-selp

3PL lean-PROG-DAT-3PL-RECIP

"They are leaning against each other."

Appendix A.2. Responses to Item 30: Giving

Number of participants: 6

Configuration: pair

Symmetry: symmetrical

Temporal organization: sequential 


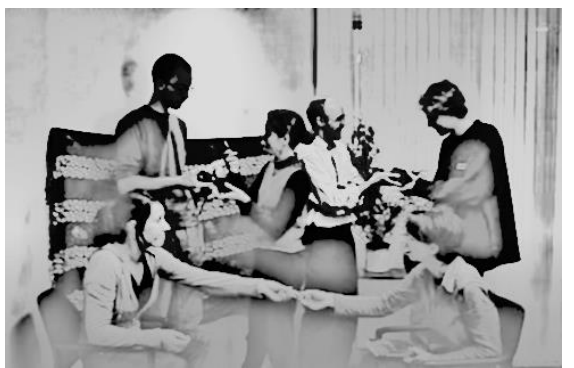

1. de sit-ing an de stand-ing

3PL sit-PROG and 3PL stand-PROG

gib-ing-de-selp

ebrithing

give-PROG-3PL-

everything

"They are sitting and they are standing, giving each other everything."

(Recip_LAC23)

2. $\mathrm{de}=\mathrm{m}$ tok-bo-de well nyuntu-k ina-ja nyampu yu

3PL=NFUT talk-DAT-3PL well 2SG-DAT DEM-EMPH DEM 2SG

teik-im-bo-yu-selp-rlang de-m tok-bo-de-selp kuja

take-TR-DAT-2SG-REFL-EMPH 3PL=NFUT talk-DAT-3PL-RECIP REL

"They say to them "well you there you take it for yourself" they say that to each other."

(Recip_LAC58)

3. de sheya-it olod-ing ebrithing

3PL share-TR whole.lot-ERG everything

"They share the whole lot, everything."

(Recip_LAC04)

Appendix A.3. Responses to Item 48: Hitting

Number of participants: 4

Configuration: chain

Symmetry: asymmetrical

Temporal organization: sequential

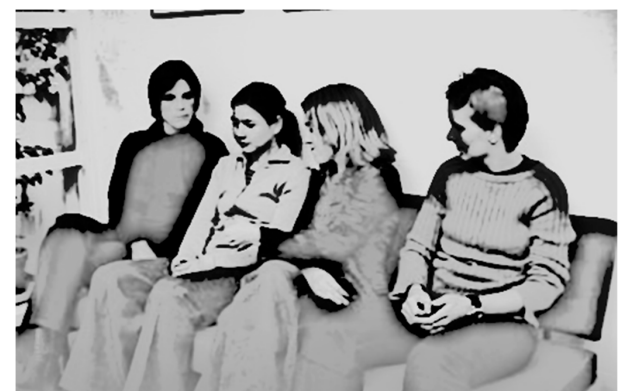

1. dei panj-ing-de-selp ni

3PL punch-PROG-3PL-RECIP knee

"They are punching each other on the knee."

(Recip_LAC23)

2. panj-de-selp-pat

punch-3PL-RECIP-ITER

"They are punching each other."

(Recip_LAC58)

3.

$\begin{array}{llll}\text { de }=\mathrm{m} & \text { hit-de-selp-pat } & \text { wan by } & \text { wan } \\ \text { 3PL=NFUT } & \text { hit-3PL-RECIP-ITER one } & \text { by } & \text { one } \\ \text { 'they hit each other one by one.' } & & \end{array}$

(Recip_LAC04)

\section{References}

Bakker, Peter. 1997. A Language of Our Own: The Genesis of Michif, the Mixed Cree-French Language of the Canadian Metis. Oxford: Oxford University Press. 
Berndt, Ronald Murray, and Catherine Helen Berndt. 1987. End of an Era: Aboriginal Labour in the Northern Territory. Canberra: Australian Institute of Aboriginal and Torres Strait Island.

Boersma, Paul. 2001. Praat, a system for doing phonetics by computer. Glot International 5: 341-45. Available online: www.praat.org (accessed on 1 September 2019).

Brown, Connor. 2020. Corpus of Kununurra Kriol. Unpublished Dataset. Perth: University of Western Australia.

Brugman, Hans, and Albert Russel. 2004. Annotating Multimedia/Multi-Modal Resources with ELAN. Paper presented at LREC 2004,Fourth International Conference on Language Resources and Evaluation, Lisbon, Portugal, May 26-28; pp. 2065-68.

Bundgaard-Nielsen, Rikke, and Carmel O'Shannessy. 2021. When more is more: The mixed language Light Warlpiri amalgamates source language phonologies to form a near-maximal inventory. Journal of Phonetics 85: 101037. [CrossRef]

Déchaine, Rose-Marie, and Martina Wiltschko. 2017. A formal typology of reflexives. Studia Linguistica 1-2: 60-106. [CrossRef]

Dickson, Greg, and Gautier Durantin. 2019. Variation in the reflexive in Australian Kriol. Asia-Pacific Language Variation 52: 171-207. [CrossRef]

Dixon, Robert M. W. 1980. The Languages of Australia. Cambridge: Cambridge University Press.

Eisenbeiss, Sonja, and William B. McGregor. 1999. The Circle of Dirt. Nijmegen: Max Planck Institute for Psycholinguistics.

Evans, N., S. C. Levinson, N. J. Enfield, A. Gaby, and A. Majid. 2004. Reciprocal constructions and situation type. In Field Manual Volume 9. Edited by A. Majid. Nijmegen: Max Planck Institute for Psycholinguistics, pp. 25-30. [CrossRef]

Evans, Nicholas, Alice R. Gaby, Stephen C. Levinson, and Asifa Majid, eds. 2011. Reciprocals and Semantic Typology. Amsterdam: John Benjamins.

Faltz, Leonard M. 1977. Reflexivization: A Study in Universal Syntax. Ph.D. thesis, University of California, Berkeley, CA, USA.

Frajzyngier, Zygmunt, and Traci Curl, eds. 1999. Reciprocals: Forms and Functions. Amsterdam: John Benjamins.

Granites, Robin Japanangka, and Mary Laughren. 2001. Semantic contrasts in Warlpiri verbal morphology: A Warlpiri's verbal view. In Forty Years on: Ken Hale and Australian Languages. Edited by Jane Simpson, David Nash, Mary Laughren, Peter Austin and Barry Alpher. Canberra: Pacific Linguistics, pp. 151-59.

Hale, Kenneth. 1973. Person marking in Walbiri. In A Festschrift for Morris Halle. Edited by Stephen R. Anderson and Paul Kiparsky. New York: Holt, Rinehart \& Winston, Inc, pp. 308-44.

Hale, Kenneth, Mary Laughren, and Jane Simpson. 1995. Warlpiri. In An International Handbook of Contemporary Research. Edited by Joachim Jacobs, Arnim von Stechow, Wolfgang Sternefeld and Theo Vennemann. Berlin: Walter de Gruyter, vol. 2, pp. 1430-49.

Harris, John. 1991. Kriol: The creation of a new language. In Language in Australia. Edited by Suzanne Romaine. Cambridge: Cambridge Univesrity Press, pp. 195-203.

Haspelmath, Martin. Forthcoming. Comparing reflexive constructions in the world's languages. In Reflexive Constructions in the World's Languages. Edited by Janic Katarzyna, Nicoletta Puddu and Martin Haspelmath. Berlin: Language Science Press.

Heine, Bernd, and Hiroyuki Miyashita. 2008. The intersection between reflexives and reciprocals: A grammaticalization perspective. In Reciprocals and Reflexives: Theoretical and Typological Explorations. Edited by Ekkerhard König and Volker Gast. Berlin: Walter de Gruyter, pp. 169-224.

Hendy, Caroline Rose. 2019. The Distribution and Acoustic Properties of Fricatives in Light Warlpiri. Unpublished Honours thesis, Australian National University, Canberra, Australia.

Hudson, Joyce. 1985. Grammatical and Semantic Aspects of Fitzroy Valley Kriol Series A. Darwin: Summer Institute of Linguistics, Australian Aborigines and Islanders Branch, vol. 8.

Hurst, Peter, and Rachel Nordlinger. 2011. Reciprocal constructions in English: Each other and beyond. In Reciprocals and Semantic Typology. Edited by Nicholas Evans, Alice R. Gaby, Stephen C. Levinson and Asifa Majid. Amsterdam: John Benjamins, pp. 75-89.

Janic, Katarzyna, Nicoletta Puddu, and Martin Haspelmath, eds. 2021. Reflexive Constructions in the World's Languages. Berlin: Language Science Press.

Konig, Ekkehard, and Volker Gast. 2008. Reciprocals and Reflexives: Theoretical and Typological Explorations. Berlin: Mouton de Gruyter.

Laughren, Mary. 1984. Warlpiri baby talk. Australian Journal of Linguistics 4: 73-88. [CrossRef]

Laughren, Mary, and Patrick McConvell. 2004. The Ngumpin-Yapa subgroup. In Australian Languages: Classification and the Comparative Method (Current Issues in Linguistic Theory). Edited by Claire Bowern and Harold Koch. Amsterdam and Philadelphia: John Benjamins, pp. 151-77.

Laughren, Mary. Forthcoming. Reflexive constructions in Warlpiri. In Reflexive Constructions in the World's Languages. Edited by Katarzyna Janic, Nicoleta Puddu and Martin Haspelmath. Berlin: Language Science Press, pp. 531-62.

Legate, Julieanne. 2002. Warlpiri: Theoretical Implications. Ph.D. thesis, Massachusetts Institute of Technology, Cambridge, MA, USA.

Levin, Beth. 1993. English Verb Classes and Alternations: A Preliminary Investigation. Chicago: Chicago University Press.

MacWhinney, Brian. 2000. The CHILDES Project: Tools for Analyzing Talk, 3rd ed. Mahwah: Lawrence Erlbaum Associates.

Majid, Asifa, Nicholas Evans, Alice R. Gaby, and Stephen C. Levinson. 2011. The semantics of reciprocal constructions across languages: An extensional approach. In Reciprocals and Semantic Typology. Edited by Nicholas Evans, Alice R. Gaby, Stephen C. Levinson and Asifa Majid. Amsterdam: John Benjamins, pp. 29-59.

Matras, Yaron. 2003. Mixed languages: Re-examining the structural prototype. In The Mixed Language Debate: Theoretical and Empirical Advances. Edited by Yaron Matras and Peter Bakker. Berlin: Mouton De Gruyter, pp. 151-76.

Matras, Yaron, and Peter Bakker. 2003. The study of mixed languages. In The Mixed Language Debate. Edited by Yaron Matras and Peter Bakker. Berlin: Mouton de Gruyter, pp. 1-20. 
McConvell, Patrick, and Felicity Meakins. 2005. Gurindji Kriol: A mixed language emerges from code-switching. Australian Journal of Linguistics 25: 9-30. [CrossRef]

Meakins, Felicity. 2011. Borrowing contextual inflection: Evidence from northern Australia. Morphology 21: 57-87. [CrossRef]

Meakins, Felicity, and Carmel O'Shannessy. 2012. Typological constraints on verb integration in two Australian mixed languages. Journal of Language Contact 52: 216-46. [CrossRef]

Munro, Jennifer. 2004. Substrate Language Influence in Kriol: The Application of Transfer Constraints to Language Contact in Northern Australia. Ph.D. Thesis, University of New England, Armidale, Australia.

Muysken, Pieter. 1981. Halfway between Quechua and Spanish: The case for relexification. In Historicity and Variation in Creole Studies. Edited by Albert Valdman and Arnold Highfield. Ann Arbor: Karoma, pp. 52-78.

Muysken, Pieter. 1997. Media Lengua. In Contact Languages: A Wider Perspective. Edited by Sarah Grey Thomason. Amsterdam: John Benjamins, pp. 365-426.

Nedjalkov, Vladimir. 2007. Reciprocal Constructions. Amsterdam: John Benjamins.

O'Shannessy, Carmel. 2004. The Monster Stories: A Set of Picture Books to Elicit Overt Transitive Subjects in Oral Texts. Unpublished work. Nijmegen: Max Planck Institute for Psycholinguistics.

O'Shannessy, Carmel. 2005. Light Warlpiri-A new language. Australian Journal of Linguistics 25: 31-57. [CrossRef]

O'Shannessy, Carmel. 2012. Code-switched input to children leads to a new mixed language. Linguistics 50: 305-40.

O'Shannessy, Carmel. 2013. The role of multiple sources in the formation of an innovative auxiliary category in Light Warlpiri, a new Australian mixed language. Language 89: 328-53. [CrossRef]

O'Shannessy, Carmel. 2016. Entrenchment of Light Warlpiri morphology. In Loss and Renewal: Australian Languages since Contact. Edited by Meakins Felicity and Carmel O'Shannessy. Berlin: De Gruyter, pp. 217-51.

O'Shannessy, Carmel. 2018. 'Bilingual acquisition and language change: A case study of Warlpiri and Light Warlpiri'. Paper presented at Keynote Talk at Workshop on Bilingual Development, Sydney, Australia, July 26-27.

O'Shannessy, Carmel. 2020. How ordinary child language acquisition processes can lead to the unusual outcome of a mixed language. International Journal of Bilingualism. [CrossRef]

O'Shannessy, Carmel. 2021a. Mixed Languages. In Routledge Handbook of Language Contact. Edited by Matras Yaron and Evangelia Adamou. London and New York: Routledge, pp. 325-48.

O'Shannessy, Carmel. 2021b. Conventionalised creativity in the emergence of a mixed language-A case study of Light Warlpiri. In Variation Rolls the Dice: A Worldwide Collage in Honour of Salikoko S. Mufwene. Edited by Enoch O. Aboh and Cécile B. Vigouroux. Amsterdam: John Benjamins.

Ponsonnet, Maïa. 2016. Reflexive, reciprocal and emphatic functions in Barunga Kriol. In Loss and Renewal: Australian Languages since Colonisation. Edited by Felicity Meakins and Carmel O'Shannessy. Berlin: De Gruyter Mouton, pp. $297-332$.

Rowse, Tim. 2002. White Flour, White Power: From Rations to Citizenship in Central Australia. Cambridge: Cambridge University Press.

RStudio_Team. 2020. RStudio: Integrated Development for R. Boston: PBC.

San Roque, Lila, Lauren Gawne, Darja Hoenigman, Julia Colleen Miller, Alan Rumsey, Stef Spronck, Nicholas Evans, and Alice Carroll. 2012. Getting the story straight: Language fieldwork using a narrative problem-solving task. Language Documentation $\mathcal{E}$ Conservation 6: 135-74.

Sandefur, John. 1979. An Australian Creole in the Northern Territory: A Description of Ngukurr-Bamyili Dialects Series B. Darwin: Summer Institute of Linguistics, Australian Aborigines and Islanders Branch, vol. 3.

Sandefur, John. 1991. A sketch of the structure of Kriol. In Language in Australia. Edited by Suzanne Romaine. Cambridge: Cambridge University Press, pp. 204-12.

Schultze-Berndt, Eva, Felicity Meakins, and Denise Angelo. 2013. Kriol. In The Survey of Pidgin and Creole Languages. English-Based and Dutch-Based Languages. Edited by Suzanne Michaelis, Philippe Maurer, Martin Haspelmath and Magnus Huber. Oxford: Oxford University Press, vol. 1, pp. 241-51.

Senft, Gunter. 2011. To have and have not: Kilivila reciprocals. In Reciprocals and Semantic Typology. Edited by Nicholas Evans, Alice R. Gaby, Stephen C. Levinson and Asifa Majid. Amsterdam: John Benjamins, pp. 225-32.

Simpson, Jane. 1991. Warlpiri Morpho-Syntax: A Lexicalist Approach. Dordrecht: Kluwer Academic Publishers.

Tasman, Maxwell Walma Japanangka, and Carmel O'Shannessy. 2020. Kaja-Warnu-Jangka 'From the Bush'. Film. Australia: PAW Media, Available online: https:/ / vimeo.com/417511570 (accessed on 15 November 2020).

Thomason, Sarah Grey. 2003. Social factors and linguistic processes in the emergence of stable mixed languages. In The Mixed Language Debate. Edited by Yaron Matras and Peter Bakker. Berlin: Mouton de Gruyter, pp. 21-40.

Thomason, Sarah Grey, and Terrence Kaufman. 1988. Language Contact, Creolization, and Genetic Linguistics. Berkeley: University of California Press. 